\title{
Development of professional behaviour with an additional experiential year in pharmacy curriculum: students' and preceptors' perspectives
}

\author{
Jennifer Van, Hafasa Mojaddidi, Catherine Nang, Mauricio Ortega, Courtney Mac Donald, Nour Itani, Baljinder \\ Kaur, Sarah Lewis, Susan Heimer, Tara Jenkins, Vanishree Rajagopalan \\ Touro University California, Vallejo, California, USA
}

\author{
Keywords \\ Curriculum \\ Pharmacy \\ PharmD \\ Preceptor \\ Professionalism \\ Student \\ Correspondence \\ Catherine Nang \\ Touro University California \\ 1310 Club Drive Vallejo \\ California \\ USA 94592 \\ cath.k.n@gmail.com
}

\begin{abstract}
Objectives: The aim of this study was to examine whether an additional year of experiential training fosters the development of professional behaviours in pharmacy students. Surveyed cohorts included experiential year one (EY1) and two (EY2) students, compared to their clinical preceptors. Methods: A validated survey instrument called APIPHANI was utilised to assess professionalism across five distinct domains that aligned with the American Pharmacists Association (AphA) toolkit. Data were analysed by a 2-tailed Mann-Whitney U test. Results: EY2 students exhibited non-statistically significant higher numerical scores than EY1 students in both Knowledge (domain 1) and Professional Involvement (domain 3), and nearly equivalent scores in Proactivity (domain 2) and Integrity (domain 5). Conclusions: These results suggest that an additional year of experiential training expands the knowledge with the EY2 students, moving closer towards the preceptors' level of knowledge. Students harboured stronger community involvement than preceptors, with the highest reported by EY2 students.
\end{abstract}

\section{Introduction}

Healthcare providers across all fields of practice are held to high standards of professionalism despite a lack of standardised definition or theoretical model to explain this concept. In Medical Professionalism in the New Millennium: A Physician Charter, professionalism amongst physicians was aptly described as 'the basis of medicine's contract with society' with fundamental principles such as serving patient interests, respecting patient autonomy, promoting social justice, and ten professional responsibilities (ABIM Foundation, 2002). In dental programs, professionalism is assessed via proficiencies, designed to encompass personal values, attitudes, and behaviours endorsed by the American Dental Education Association, having six core values: competence, fairness, integrity, responsibility, respect, and service-mindedness (ADEA, 2017). Professionalism in nursing has been defined by the Registered Nurses' Association of Ontario, Canada as a summation of knowledge, spirit of inquiry, accountability, autonomy, advocacy, innovation and visionary, collegiality and collaboration, ethics and values (RNAO, 2007).

In the United States, the Center for the Advancement of Pharmacy Education (CAPE) utilised literature from pharmacy as well as other healthcare professions to create the 2013 CAPE Educational Outcomes, which sought for pharmacy programmes to produce practiceready graduates. They formally defined professionalism as the ability to 'exhibit behaviours and values that are consistent with the trust given to the profession by patients, other healthcare providers, and society' (General Pharmaceutical Council, 2012; ACPE, 2017). The ten professional traits put forth by the Task Force on Professionalism by the American Pharmacists Association (APhA) and the American Association of Colleges of Pharmacy's (AACP) Council of Deans eloquently provided a framework for evaluation and development of professionalism (Chisholm et al., 2006). These ten traits are defined as accountability for his/her actions, commitment to self-improvement of skills and knowledge, conscience and trustworthiness, covenantal 
relationship with the client (patient), creativity and innovation, ethically sound decision-making, knowledge and skills of the profession, leadership, pride for the profession, and being service-oriented.

The importance of incorporating professionalism into pharmacy programmes became of interest internationally. The World Health Organization (WHO) and the International Pharmaceutical Federation (FIP) subsequently recommended including practical experience and patient-centred care into pharmacy curricula (Weidenmayer et al., 2006; WHO, 2016). Globally, pharmacy programmes have incorporated some aspects of professional development into their teachings in the form of experiential learning (Wallman et al., 2011), specifically required by the 2013/55/EU of the European Parliament and Council of 20 November 2013, in amended Article 44, paragraph 2 'during or at the end of the theoretical and practical training, six-month traineeship in a pharmacy which is open to the public or in a hospital under the supervision of that hospital's pharmaceutical department' (European Parliament and of the Council of EU, 2013). In the United Kingdom, registration as a pharmacist requires one year of preregistration training consisting of at least 26 weeks working in either a community or hospital setting, focused on patient-centred care. Student pharmacists are required to carefully follow a set of standards for pharmacy professionals that highlights the importance of professional development (General Pharmaceutical Council, 2012). Nordic countries utilise pharmacy internships that provide students with practical experiences and the opportunity to develop professional skills. In Sweden, pharmacy students participate in 24 weeks of introductory and advanced practical pharmacy experiences (APPEs) in community and hospital-based practice settings (Wallman et al., 2011). In contrast, pharmacy programmes in the United States employ a minimum of 36 weeks of APPEs in a myriad of practice settings.

Traditional post-baccalaureate pharmacy programmes in the United States are typically three to four years in length and yield a Doctor of Pharmacy (PharmD) degree. For most programmes, the curriculum consists of two to three years of didactic learning and one year of experiential training. Touro University California's College of Pharmacy (TUC-COP) Program is the only accredited programme in the United States that provides students with two years of experiential learning (e.g. APPEs) following two years of didactic learning. APPEs take place in a variety of health care practice settings, including community pharmacy, ambulatory care, acute care, and electives such as critical care and managed care. Within these practice settings, preceptors provide mentorship to ensure students not only acquire clinical knowledge but also develop those professional attributes described by APhA. Given the importance of experiential training to develop competency in patient-centred care, we postulated that the additional year of experiential training provided at TUC-COP would also allow for further development of professionalism in students.

As pharmacy programmes worldwide work to incorporate additional practical experience and professionalism training into their curriculums, TUC-COP's innovative structure may offer an alternative to traditional programmes to meet these dynamic and growing needs. The aim of this study was to determine whether experiential year two (EY2) students demonstrate perceptions of professionalism more similar to preceptors than experiential year one (EY1) students.

\section{Methods}

A two-part anonymous survey was administered to the experiential year two (EY2) students, experiential year one (EY1) students, and the TUC-COP preceptors. The EY1 students belonged to the pharmacy class of 2019 ( $n=88$ ), while the EY2 students were from the pharmacy class of 2020 ( $n=96$ ). TUC-COP preceptors represented the pharmacists who served as preceptors of the EY1 and EY2 students during their experiential training $(n=496)$. All surveyed student cohorts attending TUC-COP had obtained an undergraduate degree prior to their entry into the PharmD Program. The following study design was approved by the Touro University California Institutional Review Board (IRB Application \#P-0718).

A two-part anonymous survey was conducted over a duration of 8 weeks, occurring from May to July 2018. The survey was distributed at the end of the Spring term to ensure the EY1 and EY2 students had completed a majority of their experiential training for the academic year. Surveys were distributed electronically to all participants via a private email link utilising the online software, Qualtrics. Data gathered from completed surveys were subsequently filtered using inclusion and exclusion criteria as described in the data analysis and analysed for self-reported scores of professionalism using the Mann-Whitney U test (Stangroom, 2019). The MannWhitney $U$ test was methodically chosen for its capability to compare two independent populations with an ordinal dependent variable.

\section{The study tool}

The survey was divided into two parts. The first part of the survey consisted of addressed professionalism utilising a validated tool called The Assessment of Professionalism in 
Pharmacy, A Novel Instrument (APIPHANI) (Cothran, 2016; Grice et al., 2017). The APIPHANI instrument includes a series of statements that self-evaluates the professionalism and behaviours of the participants. Responses for domains $1,2,3$, and 5 were recorded using a Likert scale of 0 to 10 , with 0 defined as 'never' and 10 defined as 'always'. Domain 4 had 0 defined as 'always' and 10 as 'never'.

The APIPHANI survey meticulously evaluates professionalism based on a subset of the ten professional traits in APhA's toolkit, as seen in Figure 1. The survey consists of 37 items grouped into five domains representing distinct but vital constituents of professionalism. Domain 1 encompassed traits such as knowledge, skills, and self-learning. It assessed the level of the participant's pharmacy knowledge, as well as their willingness to seek clarification from an instructor or colleague, engage in learning opportunities through continuing education and supplemental readings such as new drug research. Domain 2 examined proactivity by assessing their willingness to take the initiative by identifying and correcting issues and prioritising tasks. Domain 3 explored accountability, involvement, care, and dedication. It evaluated the participant's devotion and commitment to the pharmacy profession measured by their participation in national organisations, involvement in community outreach, and dedication to their patients. Domain 4 represented traits of altruism, responsibility, and moral courage. It explored circumstances for abiding laws, self-accountability for tardiness, and situations such as 'ignoring injustices for fear of being among the minority.

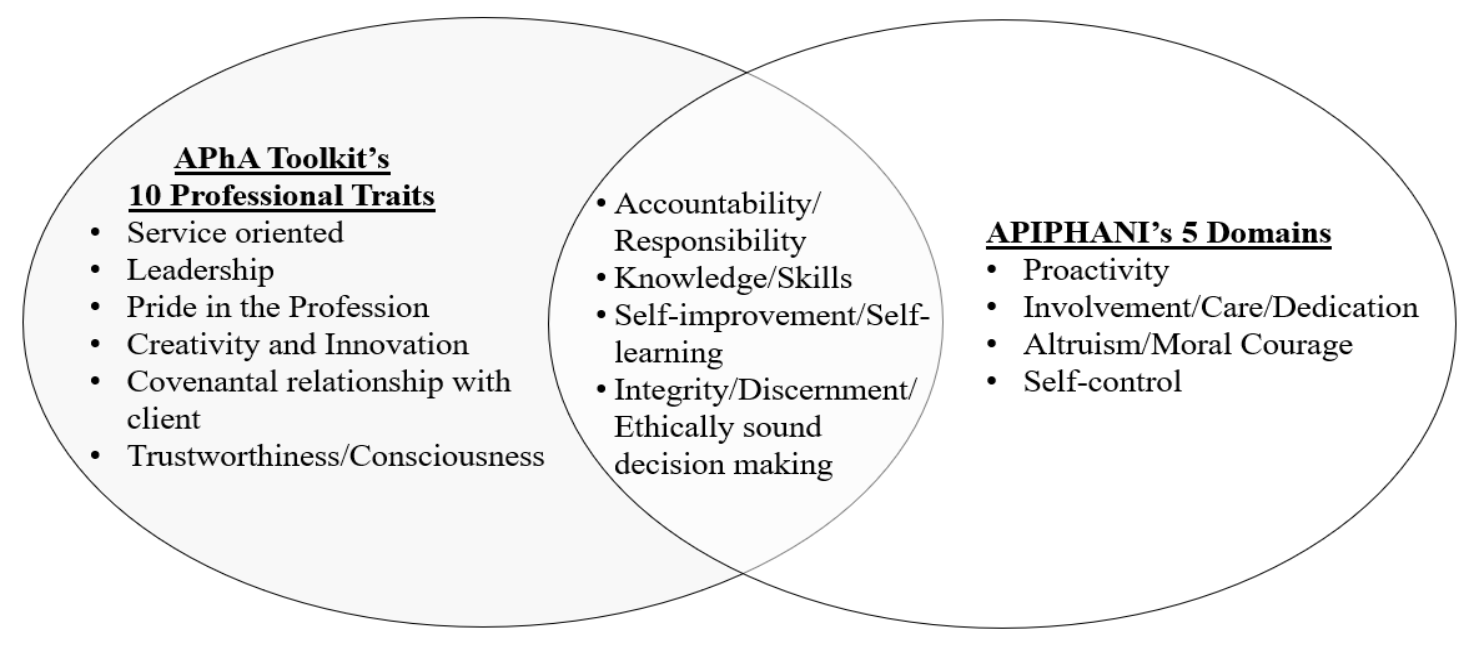

Abbreviations: $\mathrm{APhA}=\mathrm{American}$ Pharmacists Association, APIPHANI=Assessment of Professionalism in Pharmacy, A Novel Instrument

The APIPHANI's 5 domains coincide with the ten professional traits expressed in the Pharmacy Professionalism Toolkit developed by APhA. As such, it was used in this study to evaluate the alignment of professionalism between preceptors and students.

Figure 1: Five domains of APIPHANI and ten professional traits of the APhA toolkit

The survey questions representing this domain were recorded with a reverse Likert Scale, i.e. 0 was defined as 'always' and 10 as 'never.' Domain 5 investigated selfcontrol, integrity, and discernment by determining the degree to which a participant would protect their patient's privacy and health information. For simplicity, each domain will now be addressed throughout this paper as Knowledge (Domain 1), Proactivity (Domain 2), Professional Involvement (Domain 3), Responsibility (Domain 4), and Integrity (Domain 5). Each domain had different scoring ranges: Knowledge, Proactivity, Professional Involvement, and Integrity had minimum scores of 0 with the ideal goal scores of $80,60,60$, and 70 , respectively. Responsibility (Domain 4) is designed differently from the other domains, with an ideal score of 0 out of 90 possible points. The overall variation in scoring is due to the different number of questions used to assess each domain in the APIPHANI instrument.

The second part of the survey consisted of a series of questions pertaining to the participant's demographics, including age, gender, and categorisation as either an EY1 or EY2 student or preceptor.

\section{Data analysis}

\section{Inclusion/exclusion criteria}

Survey responses submitted through Qualtrics were only included if all of the following criteria were met: 
participants stated consent, answered a minimum of four questions per each domain, and self-identified themselves as either EY1, EY2, or a preceptor affiliated with TUC-COP. Responses were excluded from analysis if participants retracted consent, failed to answer three or fewer questions in the same domain, or failed to identify as either an EY1 or EY2 student or a preceptor.

\section{Statistical analysis}

For responses meeting the inclusion criteria, the sums of each domain were calculated for each individual respondent. These values were inputted into the MannWhitney U test accessible via the Social Sciences Statistics website (Stangroom, 2019). Individual results were aggregated to form an average domain score for the responders' respective cohort.

\section{Results}

The demographic characteristics of EY1, EY2, and preceptors are presented in Tables I and II, respectively. The EY1 cohort consisted of 88 participants, of which 38 survey responses fell within the inclusion criteria, resulting in a response rate of $43 \%$. Most participants were female $(n=26,68 \%)$ in the age range of $23-28(n=25$, $66 \%$ ) (Table I). The EY2 cohort consisted of 96 participants, of which 55 responses met the inclusion criteria, resulting in a response rate of $57 \%$. Similar to the EY1 group, most EY2 participants were also female $(n=32,58 \%)$ and in the age range of $23-28(n=31,56 \%)$ (Table I).

Table I: Demographics of experiential Year 1 and experiential Year 2 students

\begin{tabular}{lcc}
\hline Age, $\mathbf{n}(\%)$ & EY1 $(\mathbf{n = 3 8 )}$ & EY2 (n=55) \\
\hline $23-28$ & $25(66 \%)$ & $31(56 \%)$ \\
$29-32$ & $4(11 \%)$ & $18(33 \%)$ \\
$32+$ & $5(13 \%)$ & $3(5 \%)$ \\
\hline Gender, $\mathbf{n}(\%)$ & $11(29 \%)$ & $23(42 \%)$ \\
\hline Male & $26(68 \%)$ & $32(58 \%)$ \\
\hline
\end{tabular}

From the 88 participants, 38 responses were accepted, with a majority of EY1 students being female $(n=26,68 \%)$ in the age range of 23-28 $(n=25,66 \%)$. Similar demographics are seen in the EY2 cohort with 55 accepted survey responses of 99 participants, a majority being female $(n=32,58 \%)$ in the age range of $23-28$ $(n=31,56 \%)$.
The preceptor cohort included 453 pharmacists, of which 90 survey responses matched the inclusion criteria, resulting in a response rate of $20 \%$, which is acceptable secondary to a prudent study methodology by Meszaros and authors (2013). The majority of the preceptors were female $(n=52,58 \%)$ and were in the age range of $35-44(n=29,32 \%)$. In addition, $72 \%(n=65)$ of the preceptors included in our analysis have precepted both EY1 and EY2 students (Table II).

Table II: Demographics of preceptors

\begin{tabular}{|c|c|}
\hline Age, n (\%) & Preceptors $(n=90)$ \\
\hline $25-34$ & $27(30 \%)$ \\
\hline $35-44$ & $29(32 \%)$ \\
\hline $45-54$ & $13(14 \%)$ \\
\hline $55-64$ & $13(14 \%)$ \\
\hline $65-74$ & $3(3 \%)$ \\
\hline Unanswered & $5(6 \%)$ \\
\hline \multicolumn{2}{|l|}{ Gender, n (\%) } \\
\hline Male & 35 (39\%) \\
\hline Female & $52(58 \%)$ \\
\hline Prefer not to disclose & $1(1 \%)$ \\
\hline Unanswered & $2(2 \%)$ \\
\hline \multicolumn{2}{|l|}{ Years in practice, $\mathbf{n}(\%)$} \\
\hline $0-5$ years & $40(44 \%)$ \\
\hline $6-10$ years & $25(28 \%)$ \\
\hline $11-15$ years & $11(12 \%)$ \\
\hline $16-20$ years & $5(6 \%)$ \\
\hline $26-30$ & $4(4 \%)$ \\
\hline Over 31 years & $1(1 \%)$ \\
\hline Unanswered & $3(3 \%)$ \\
\hline \multicolumn{2}{|c|}{ Level of students precepted, $n$ (\%) } \\
\hline Both EY1 and EY2 students & $65(72 \%)$ \\
\hline EY1 students & $3(3 \%)$ \\
\hline EY2 students & $18(20 \%)$ \\
\hline Unanswered & $3(3 \%)$ \\
\hline
\end{tabular}

Ninety survey responses were accepted in the preceptor cohort of the 453 surveys that were sent out. A majority of the preceptors were female $(n=52,58 \%)$ and were in the age range of $35-44(n=29,32)$. From the accepted survey responses, $72 \%$ $(n=65)$ of the accepted responses from preceptors precepted both EY1 and EY2 students. 
A comparison of survey scores between all cohorts of participants is shown in Figure 2 and Table III. In the Knowledge domain, with the highest possible score being an 80, the average score for EY1s was 53.02, EY2s was 55.49, and the preceptors was 59.67. As for the Proactivity domain, the highest possible score was 60 . The EY1s and EY2s scored very similarly, while the preceptor score was higher (EY1 47.84, EY2 47.41, preceptor 52.57). The best possible score in the Professional Involvement domain was 60 . Both student groups scored higher than the preceptor group (average score EY1 39.92, EY2 41.49, preceptors 37.36). In the Responsibility domain, a zero was the best possible score. Interestingly, the average score for EY1s was closer to the preceptor's average score versus the EY2s (EY1 21.29, EY2 31.72, preceptor 12.53). For the Integrity domain, all three groups' average scores were almost identical (61.94, 61.45, and 63.73, respectively). Statistically significant differences were seen between EY1 students and preceptors in Knowledge, Proactivity, and Responsibility $(p<0.5)$. However, EY1 students responded similarly to preceptors for Professional Involvement and Integrity $(p>0.05)$. The comparison between EY2 students and preceptors displayed statistical differences in Knowledge, Proactivity, Professional Involvement, and Responsibility $(p<0.05)$. There was no difference observed between EY2 students and preceptors for Integrity $(p>0.05)$.

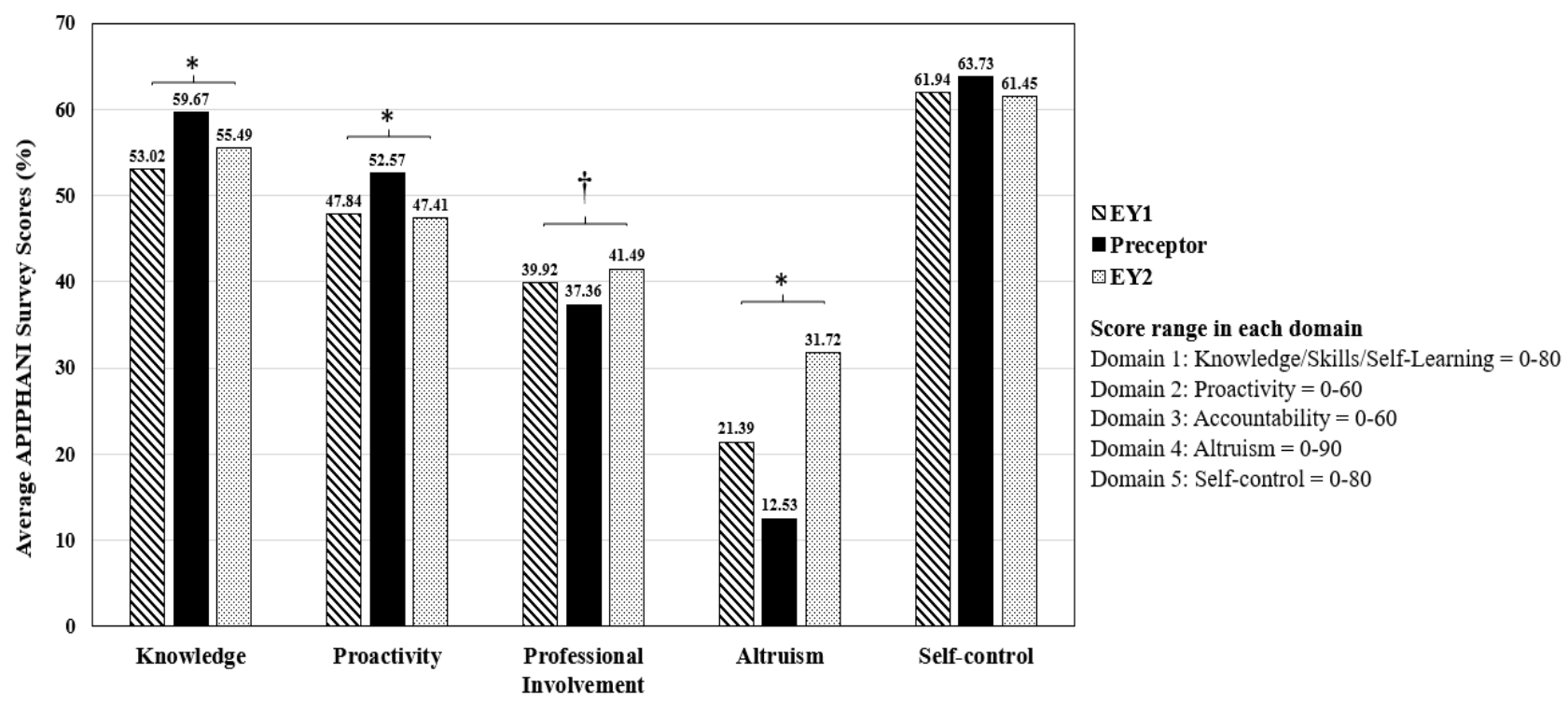

Abbreviations: EY1=Experiential Year 1, EY2=Experiential Year 2, Domain 1=Knowledge, Domain 2=Proactivity, Domain 3=Professional Involvement, Domain 4=Responsibility, Domain 5=Integrity.

*=Statistical difference seen between EY1 and EY2 students compared to preceptors $(p<0.05)$.

$\dagger=$ Statistical difference seen between EY2 and preceptors only $(p<0.05)$.

Average scores of APIPHANI survey in each cohort. EY1 students compared to preceptors demonstrated similar perceptions of professionalism in Domain 3 and 5 ( $\mathrm{p}<0.05$ ). EY2 students demonstrated similar perceptions only in Domain $5(\mathrm{p}<0.05)$. The most apparent nonalignment with between both EY1 and EY2 students compared to preceptors was seen in Domain 4.

Figure 2: Average scores of APIPHANI survey between experiential Year 1 students, experiential Year 2 students and preceptors

The aim of the study was to assess whether an additional experiential year aids in the development of professionalism in pharmacy students. As shown in Figure 2, both student cohorts exhibited higher average scores in Professional Involvement than preceptors. The EY2 students scored the highest (41.49), and the EY1 trailed slightly behind them (39.92), while the preceptors scored lower than the EY1 and EY2 students in this domain (37.36), as shown in Table III and Figure 2.
As expected, Knowledge was the highest amongst preceptors who have several years of professional experience. The preceptors scored 59.67, exceeding the knowledge scores of both student groups. Although not statistically significant, the EY2 students scored higher (55.49) than EY1 students (53.02) in this domain. 
Table III: Total average scores of the APIPHANI survey

\begin{tabular}{lccccc}
\hline & Knowledge & Proactivity & Professional involvement & Responsibility & Integrity \\
\hline EY1 $(n=38)$ & 53.02 & 47.84 & 39.92 & 21.39 & 61.94 \\
EY2 $(n=55)$ & 55.49 & 47.41 & 41.49 & 31.72 & 61.45 \\
Preceptor $(n=90)$ & 59.67 & 52.57 & 37.36 & 12.53 & 63.73
\end{tabular}

Average scores in each cohort are stated above. Notably, preceptors scored the lowest in Professional Involvement and EY1/2 students scored greater, with EY2 students having the highest total score.

\section{Discussion}

Professionalism in the healthcare industry has been a valued construct for patient-centred care. As elucidated by the WHO and the FIP, experiential courses emphasising patient-centred care are increasingly being incorporated into pharmacy curricula around the globe (Wiedenmayer, 2016; WHO, 2016). Theoretically, the immersion of students in such advanced experiential courses or internships increases self-awareness, confidence, and self-motivation. Altogether, professional exposure provides an easier transition from a student intern to an independent practitioner (Coulehan, 2005).

In this study, the authors sought to investigate whether an additional experiential year within pharmacy school would cultivate professional traits in students that are in closer alignment with their preceptors, who are working professionals. The survey results revealed that both EY1 and EY2 students reported similar perceptions as preceptors in Integrity (domain 5). The Integrity domain appraises one's ability to protect a patient's privacy and health information. As integrity constitutes an indispensable component of any healthcare profession, this construct is impressed upon students beginning at matriculation into pharmacy school. From the symbolic white coat and pinning ceremonies where students take the pharmacist's oath to numerous opportunities for patient counselling and patient advocacy that occur prior to entering their experiential training, pharmacy students are coached and prepared to recognise the importance of integrity. The alignment of scores amongst the surveyed cohorts in the integrity domain is indicative of students acquiring this quintessential attribute and is reflective of highly successful pedagogy.

When examining perceptions in Professional Involvement (domain 3), a fascinating finding emerged as students outscored their preceptors. A closer investigation into this phenomenon unveiled that EY2 students reported higher levels of professional engagement than both EY1 students and preceptors. Although this study's hypothesis predicted that a score similar to those of the preceptors would signify greater professional development in students, this was not observed in the domain of Professional Involvement. The prediction was based on the assumption that the preceptors had been in the profession longer; they would score the highest among the three surveyed populations, demonstrating higher levels of community outreach and greater involvement in professional organisations. However, the preceptors scored the lowest in this domain, demonstrating a negative correlation. It is not clear whether this negative finding could be impactful. The difference in the overall score may be due to one question in the survey linked to the participation in community outreach and community events in which the preceptors scored the lowest. On the other hand, very few EY1 and EY2 students had a low score for this particular question. One explanation could be that preceptors devote less time to community outreach and volunteering due to time constraints posed by longer working hours. In contrast, students may have requirements to volunteer in activities built into their curriculum, and therefore students are more motivated to participate in such activities. This divergence may be further explained by diversity in training.

TUC-COP preceptors obtain training from a multitude of pharmacy schools nationwide, some of which may not have emphasised the importance of pharmacy organisation involvement and community outreach. Conversely, at TUC-COP, great emphasis is placed on social justice and community engagement during the didactic portion of the curriculum. This is manifested by practising counselling education through professional competitions and workshops, practising diabetes and hypertension patient screening techniques with mentors, and lobbying for policy changes by educating government legislators. Consequently, these students are inspired to join pharmacy organisations that coordinate such events and emphasize the importance 
of improving the community through outreach, education, and involvement. As EY2 students prepare to join the workforce as practising interns and later pharmacists, these principles are reinforced as students begin to network with other pharmacy professionals by attending national meetings and events. All the above reasons might explain why the experiential student cohorts scored higher than their preceptors in the professional involvement domain.

This study's findings disclosed that both student cohorts departed from their preceptors in Knowledge, Proactivity, and Responsibility (domains 1, 2, and 4). This expected distinction in Knowledge can be attributed to students being newly introduced to pharmacy practice settings and still learning to strengthen their knowledge base required to practice. In contrast, preceptors are more likely to pursue higher-order thinking and self-directed learning in their practice, having already established a sound knowledge base required to become pharmacists. Thus, the desire to seek additional knowledge may be minimal in students since their fundamental pharmacy knowledge has not yet been solidified.

Similarly, Proactivity (domain 2) posed a synonymous challenge for students navigating rotations. While experiential students are still learning to apply their didactic knowledge to clinical settings, preceptors who are adept in practising tend to take more initiative and are more proactive in their practice setting to enhance their skills in order to improve the health outcomes of their patients.

Likewise, the disparity among the student and preceptor cohorts observed in Responsibility (domain 4) which was linked to altruism, responsibility, and moral courage, maybe due to students lacking the freedom of practice permitted to licensed pharmacists, and therefore being unable to make decisions independently on behalf of their patients.

There were several limitations in this study. Due to the timing of the survey, some students erroneously chose their experiential year, which led to several students being excluded from the study. Furthermore, a handful of EY2 students had not completed all of their rotations prior to their anticipated graduation. As a result, the EY2 student cohort was not a homogenous population consisting of students who completed all of their rotations. The response rate of this study was low, with $20 \%$ in the preceptor cohort, $43 \%$ in the EY1 cohort, and $57 \%$ in the EY2 cohort.

Overall, with respect to professionalism, this study was unable to conclusively inform that an additional experiential year contributed to a better alignment between students and preceptors, though there was a clear trend in that direction with respect to the Knowledge domain (domain 1). However, TUC-COP's high-stakes exam, called the triple jump exam (TJE), has been a robust predictor of the performance of students in their APPEs compared to any other traditional and non-traditional test scores in the didactic courses (Meszaros, 2009). Other modalities implemented by TUC-COP to ensure students are clinically ready for APPEs includes bi-yearly Objective Structured Clinical Examinations (OSCEs) and the Practice Assessment of Competence at Entry (PACE) exam, which takes place at the conclusion of students' didactic education. Nevertheless, there is no formal standalone professionalism assessment prior to embarking upon experiential curricula. Understanding the need to better equip rotating students with training in professionalism, TUC-COP has recently incorporated mandatory professionalism courses within their experiential curricula with the intent of evolving student perspectives. These monthly meetings include guest lecturers who cover an extensive variety of topics such as career development, professional development, conflict management, and pharmacy law discussions.

While there are a number of strengths from completing a programme with an extra experiential year, there are some weaknesses to be considered. With an accelerated two years of didactic learning and an additional year of experiential learning compared to other traditional programmes, there is the possibility of burnout among students.

Although this study focused on the impact of professionalism with an additional experiential year, the supplemental opportunities provided to the students is pivotal and worth mentioning. The increase in networking opportunities for students boosts their confidence and the relationships they build with various healthcare professionals. This is unique since the TUC-COP curriculum affords students to spend additional time in community pharmacy, ambulatory care and acute care practice settings as well as speciality settings such as clinical and preclinical research, pharmacy academia, food and drug administration, pharmacy advocacy etc. As a result, TUC-COP students are able to explore additional fields of pharmacy, acquiring more exposure to pharmacistdelivered patient-centred care and independent learning that undoubtedly strengthens their professional and personal growth. 


\section{Conclusion}

Professionalism is fundamental to pharmacy practice, but due to its abstract nature and encompassing wideranging behaviours, it is exceedingly difficult to study and teach. TUC-COP's incorporation of an additional experiential year into its pharmacy curriculum has sought to provide students with added patient care experiences designed to further promote professionalism traits amongst its students. This additional experiential year complements the TUCCOP's pharmacy curriculum that is rooted in patient advocacy and community involvement. The striking similarity in integrity symbolically bridges students to their preceptors in a crucial domain that forms the basis of successful practitioners in any healthcare industry. Importantly, a departure amongst EY1 and EY2 students occurs in Knowledge and Professional Involvement as EY2 students move closer to their preceptors, alluding to a growth in professionalism that occurs in the second experiential year. Although our study explored professionalism through a validated survey tool encompassing various aspects of professionalism, utilising other assessment tools to measure professionalism may highlight alternative areas where an additional experiential year might impact professional development. Additionally, further research on how patients are impacted by students in different stages of experiential learning could provide insights into the progress made in their mastery of the various professionalism traits.

\section{References}

ABIM Foundation. American Board of Internal Medicine, ACP-ASIM Foundation. American College of PhysiciansAmerican Society of Internal Medicine, \& European Federation of Internal Medicine. (2002). Medical professionalism in the new millennium: a physician charter. Annals of internal medicine, 136(3), 243-246. https://doi.org/10.7326/0003-4819-136-3-20020205000012

ADEA Statement on Professionalism in Dental Education: (As approved by the 2009 ADEA House of Delegates). (2017). Journal of dental education, 81(7), 885-890. Available at: https://www.adea.org/documents/Section3/(3.2.5)-ADEAStatement-on-Professionalism-in-Dental-Education.pdf

Accreditation Council for Pharmacy Education. (2016). Accreditation standards and key elements for the professional program in pharmacy leading to the doctor of pharmacy degree (online). Available at: https://www.acpeaccredit.org/pdf/Standards2016FINAL.pdf

Bimray, P., Jooste, K., \& Julie, H. (2019). Professionalism experiences of undergraduate learner nurses during their 4year training programme at a Higher Education Institution in the Western Cape, South Africa. Curationis, 42(1), e1-e8. https://doi.org/10.4102/curationis.v42i1.2030

Boyle, C. J., Beardsley, R. S., Morgan, J. A., \& Rodriguez de Bittner, M. (2007). Professionalism: a determining factor in experiential learning. American journal of pharmaceutical education, 71(2), 31. https://doi.org/10.5688/aj710231

Chisholm, M. A., Cobb, H., Duke, L., McDuffie, C., \& Kennedy, W. K. (2006). Development of an instrument to measure professionalism. American journal of pharmaceutical education, 70(4), 85. https://doi.org/10.5688/aj700485

Cothran, K.L. (2016). A study to determine the validity of a self-assessment instrument of professionalism in pharmacy. Diss. Saint Louis University

Coulehan J. (2005). Viewpoint: today's professionalism: engaging the mind but not the heart. Academic medicine: journal of the Association of American Medical Colleges, 80(10), 892-898. https://doi.org/10.1097/00001888200510000-00004

Cruess, R. L., \& Cruess, S. R. (2006). Teaching professionalism: general principles. Medical teacher, 28(3), 205-208. https://doi.org/10.1080/01421590600643653

Directive 2005/36/EC of the European Parliament and of the Council of 7 September 2005 on the recognition of professional qualifications (Text with EEA relevance). Off $J$ Europ Union L, 255, 22-142. Available at: https://eurlex.europa.eu/legal-

content/EN/TXT/?uri=celex\%3A32005L0036

Directive 2013/55/EU of the European Parliament and of the Council of 20 November 2013 amending Directive 2005/36/EC on the recognition of professional qualifications and Regulation (EU) No 1024/2012 on administrative cooperation through the Internal Market Information System ('the IMI Regulation') (Text with EEA relevance). Available at: https://eur-lex.europa.eu/legalcontent/EN/TXT/?uri=CELEX\%3A32013L0055

Eukel, H., Frenzel, J., Skoy, E., \& Faure, M. (2018). Longitudinal evaluation of student professionalism throughout the professional didactic curriculum of a pharmacy program. Currents in pharmacy teaching \&

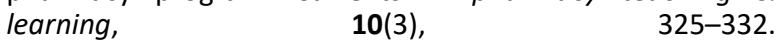
https://doi.org/10.1016/j.cptl.2017.11.011

General Pharmaceutical Council [GPhC]. (2011). Future pharmacists: Standards for the initial education and training of pharmacists (online). Available at: https://www.pharmacyregulation.org/sites/default/files/do cument/gphc_future_pharamcists_may_2011.pdf

General Pharmaceutical Council. (2012). Criteria for registration as a pharmacist. Available at: https://www.pharmacyregulation.org/sites/default/files/Re gistration\%20criteria\%20for\%20pharmacists\%20September \%202012_0.pdf

Grice, G.R., Gaebelain, C.J., Cothran, K., Geslani, G., \& Ding, C. (2017). Assessment of Professionalism in Pharmacy, A Novel Instrument (APIPHANI). 118th Annual Meeting of the American Association of Colleges of Pharmacy. Nashville, Tennessee. July 15-19, 2017

Hammer D. (2006). Improving student professionalism during experiential learning. American journal of pharmaceutical education, 70(3), 59. https://doi.org/10.5688/aj700359 
Hammer D. (2000). Professional attitudes and behaviors: The "A's and B's" of professionalism. American journal of pharmaceutical education, 60(4). Available at: http://archive.ajpe.org/legacy/ajpe_metaview.asp?ID=591

Huddle, T. S., \& Accreditation Council for Graduate Medical Education (ACGME). (2005). Viewpoint: teaching professionalism: is medical morality a competency. Academic medicine: journal of the Association of American Medical Colleges, 80(10), 885-891. https://doi.org/10.1097/00001888-20051000000002

Hutchings, H.A, \& Rapport, F. (2012). Patient-centered professionalism. Patient Intelligence, 4, 11-21. https://doi.org/10.2147/PI.S19821

Kelley, K. A., Beatty, S. J., Legg, J. E., \& McAuley, J. W. (2008). A progress assessment to evaluate pharmacy students' knowledge prior to beginning advanced pharmacy practice experiences. American journal of pharmaceutical education, 72(4), 88. https://doi.org/10.5688/aj720488

Lonie, J. M., Marzella, N., Perry, R., Shah, B., \& Jariwala, J. (2015). Pharmacists levels of emotionality and career success correlates: an exploratory study. Journal of pharmacy practice, 28(3), 256-260. https://doi.org/10.1177/0897190013516502

Maudsley, G., \& Strivens, J. (2000). Promoting professional knowledge, experiential learning and critical thinking for medical students. Medical education, 34(7), 535-544. https://doi.org/10.1046/j.1365-2923.2000.00632.x

Mészáros, K., Barnett, M. J., Lenth, R. V., \& Knapp, K. K. (2013). Pharmacy school survey standards revisited. American journal of pharmaceutical education, 77(1), 3. https://doi.org/10.5688/ajpe7713

Mészáros, K., Barnett, M. J., McDonald, K., Wehring, H., Evans, D. J., Sasaki-Hill, D., Goldsmith, P. C., \& Knapp, K. K. (2009). Progress examination for assessing students' readiness for advanced pharmacy practice experiences. American journal of pharmaceutical education, 73(6), 109. https://doi.org/10.5688/aj7306109

Nunes-da-Cunha, I., Arguello, B., Martinez, F. M., \& Fernandez-Llimos, F. (2016). A Comparison of PatientCentered Care in Pharmacy Curricula in the United States and Europe. American journal of pharmaceutical education, 80(5), 83. https://doi.org/10.5688/ajpe80583

Registered Nurses' Association of Ontario. (2007). Professionalism in nursing. Toronto, Canada: Registered Nurses' Association of Ontario. Available at: https://rnao.ca/sites/rnaoca/files/Professionalism_in_Nursing.pdf

Selic, P., Cerne, A., Klemenc-Ketis, Z., Petek, D., Svab, I. (2019). Attitudes toward professionalism in medical students and its associations with personal characteristics and values: a national multicentre study from Slovenia raising the question of the need to rethink professionalism. Advances in Medical Education and Practice, 10, 437-446. https://doi.org/10.2147/AMEP.S197185

Smith, M. G., \& Dinkins, M. M. (2015). Early Introduction to Professional and Ethical Dilemmas in a Pharmaceutical Care Laboratory Course. American journal of pharmaceutical education, 79(10), 156. https://doi.org/10.5688/ajpe7910156

Stangroom, Jeremy (2019), Social Science Statistics: Mann-Whitney $U$ Test Calculator. Available at: https://www.socscistatistics.com/tests/mannwhitney/
Steinert, Y., Cruess, S., Cruess, R., \& Snell, L. (2005). Faculty development for teaching and evaluating professionalism: from programme design to curriculum change. Medical education, 39(2), 127-136. https://doi.org/10.1111/j.13652929.2004.02069.x

Swick H. M. (2000). Toward a normative definition of medical professionalism. Academic medicine: journal of the Association of American Medical Colleges, 75(6), 612-616. https://doi.org/10.1097/00001888-200006000-00010

Wald, H. S., Davis, S. W., Reis, S. P., Monroe, A. D., \& Borkan, J. M. (2009). Reflecting on reflections: enhancement of medical education curriculum with structured field notes and guided feedback. Academic medicine: journal of the Association of American Medical Colleges, 84(7), 830-837. https://doi.org/10.1097/ACM.0b013e3181a8592f

Wallman, A., Sporrong, S.K., Gustavsson, M., Kettis Lindblad, A.., Johansson, M. \& Ring, L., (2011). Swedish students' and preceptors' perceptions of what students learn in a sixmonth advanced pharmacy practice experience. American Journal of Pharmaceutical Education, 75(10), article 197. https://doi.org/10.5688/ajpe7510197

WHO, 2016. Framework on integrated people-centered health services: an overview. Available at: https://apps.who.int/gb/ebwha/pdf_files/WHA69/A69_39en.pdf?ua $=1 \& u a=1$

Wiedenmayer, Karin, Summers, Rob S, Mackie, Clare A, Gous, Andries G. S, Everard, Marthe. et al. (2006). Developing pharmacy practice: a focus on patient care: handbook, 2006 ed. World Health Organization. Available at: https://www.fip.org/files/fip/publications/DevelopingPhar macyPractice/DevelopingPharmacyPracticeEN.pdf 